\title{
Calculi in the Prostatic Utricle Communicated with an Ejaculatory Duct
}

\author{
Mi-Sun Hur $\mathbb{D}^{1}$, Chang-Seok Oh $\mathbb{D}^{2}$, In-Hyuk Chung ${ }^{3}$ \\ ${ }^{1}$ Department of Anatomy, Catholic Kwandong University College of Medicine \\ ${ }^{2}$ Department of Anatomy and Cell Biology, Sungkyunkwan University School of Medicine \\ ${ }^{3}$ Department of Anatomy, Yonsei University College of Medicine
}

\begin{abstract}
We have observed a case of calculi in the prostatic utricle (PU) which suggests a different formation mechanism of calculi in the PU and reflects the variety of the PU. Several calculi were observed in the sac of the PU, which was filled with a homogenous, yellowish, jelly-like material. The material was also evident in the left ejaculatory duct. The orifice of the PU appeared as an open slit in the center of the seminal colliculus. The two openings of the ejaculatory ducts were not evident on the seminal colliculus. The apparent absence of the openings of the two ejaculatory ducts on the seminal colliculus might have been due to obstruction, possibly caused by chronic inflammation or injury to the seminal colliculus. The resulting increased pressure in the ejaculatory duct might have perforated the thin wall between the ejaculatory duct and the PU. The seminal fluid that might have entered the PU through a fistula might not have flowed easily into the prostatic urethra because the utricular orifice had a very narrow slit-shaped aperture. It appeared that the seminal fluid that accumulated in the PU had enlarged the structure, and was concentrated into several foci associated with the formation of the calculi during its long-lasting stasis.
\end{abstract}

Keywords : Calculus, Prostatic utricle, Ejaculatory duct, Seminal colliculus, Prostate

\section{INTRODUCTION}

The prostatic utricle (PU) is a cul-de-sac between the ejaculatory ducts that opens into the prostatic urethra through a round or slit-like aperture [1-3], and its morphology was classified into three types based on the location of its pouch [4]. Since the presence of calculus in the prostatic utricle in two patients was reported [5], the calculus has been known to form by urinary stasis and possible infection in the PU [6,7] and to cause hematospermia [8]. We have observed a case of the calculi in the PU that suggested a different formation mechanism.

The author(s) agree to abide by the good publication practice guideline for medical journals.

The author(s) declare that there are no conflicts of interest.

Received: November 27, 2020; Revised: December 8, 2020;

Accepted: December 10, 2020

Correspondence to: Chang-Seok Oh (Department of Anatomy and Cell Biology, Sungkyunkwan University School of Medicine, Suwon 16419, Republic of Korea)

E-mail: changoh@skku.edu

IH Chung passed away on 4th Jan, 2020.

\section{CASE REPORT}

The prostate of a male cadaver (age, 83 years) was dissected. The dome-shaped roof of the sac of the enlarged PU reached over the level of commencement of the ejaculatory ducts by the ductus deferenses and the seminal vesicles. 

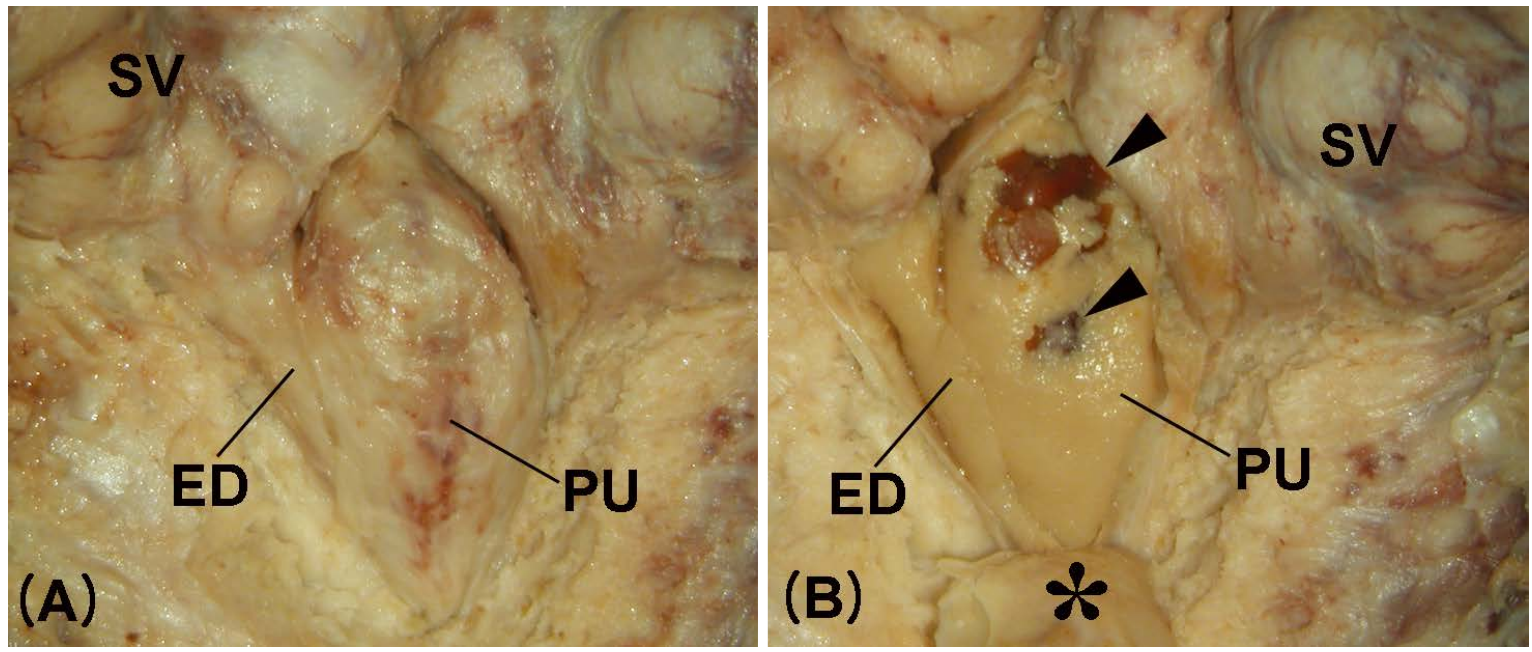

Fig. 1. (A) The prostatic utricle (PU), the left ejaculatory duct (ED), and the seminal vesicle (SV) are seen. (B) The PU and the ED are opened by retracting their walls (asterisk) distally. Several calculi (arrowheads) are evident in the PU.

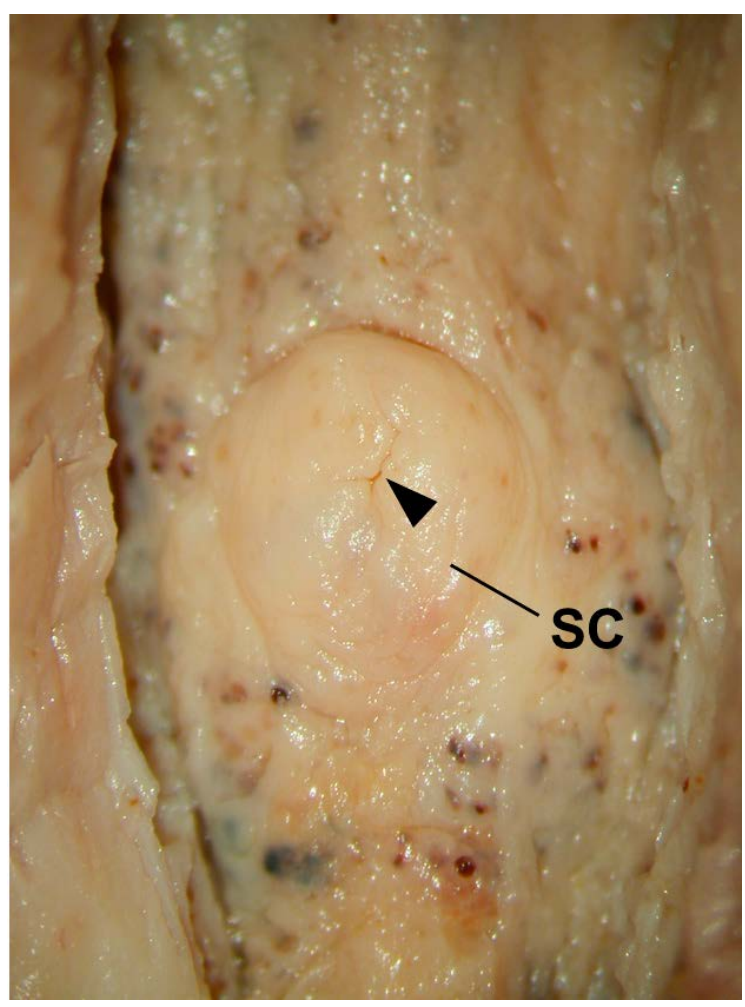

Fig. 2. Magnified view of the oval-shaped seminal colliculus (SC) showing the utricular slit-shaped orifice (arrowhead).

The maximal width and length dimensions of the PU were 9.13 and $20.0 \mathrm{~mm}$, respectively. The left ejaculatory duct was intimately adherent to the enlarged PU, and the right ejaculatory duct was compressed beneath the PU (Fig. 1A).
Several calculi were observed around the middle and in the upper half of the sac of the PU, which was filled with homogenous yellowish jelly-like material. The material was continuously evident in the left ejaculatory duct (Fig. 1B). The seminal colliculus was located in the distal threefourths on the prostatic urethra. It was oval in shape, and its width and length were 5.22 and $8.69 \mathrm{~mm}$, respectively. The orifice of the PU appeared as an open slit in the center of the seminal colliculus. The two openings of the ejaculatory ducts were not evident on the seminal colliculus (Fig. 2).

\section{DISCUSSION}

Calculi in PU have been reported to result from urinary stasis and consequent infection $[5,6]$. However, the caluli in the PU in the present case suggested that they can also form by stasis of the seminal fluid, as indicated by the PU being filled with the same homogenous yellowish material present in an ejaculatory duct. The apparent absence of the openings of the two ejaculatory ducts on the seminal colliculus might have been due to obstruction of the openings, possibly caused by chronic inflammation or injury to the seminal colliculus. The resulting increased pressure in the ejaculatory duct might have perforated the thin wall between the ejaculatory duct and the PU. The seminal fluid entering the PU through the fistula might not have flowed easily into the prostatic urethra because the utricular orifice had a very narrow slit-shaped aperture. 
It appeared that the seminal fluid that accumulated in the PU had enlarged the structure and was concentrated into several foci associated with the formation of the calculi in the PU during its long-lasting stasis.

\section{CONFLICTS OF INTEREST}

None declared.

\section{REFERENCES}

1. Clement CD. Gray's anatomy $30^{\text {th }}$ American ed. Philadelphia: Lea \& Febiger; 1985.

2. Rosse C, Gaddum-Rosse P. Hollinshead's textbook of anato- my. $5^{\text {th }}$ ed. Philadelphia: Lippincott-Raven; 1997.

3. Moore KL, Dalley AF. Clinically oriented anatomy. $5^{\text {th }}$ ed. Philadelphia: Lippincott Williams \& Wilkins; 2006.

4. Oh CS, Chung IH, Won HS, Kim JH, Nam KI. Morphologic variations of the prostatic utricle. Clin Anat. 2009;22:35864.

5. Spence HM, Chenoweth VC. Cysts of the prostatic utricle (M?llerian duct cysts): report of two cases in children, each containing calculi, cured by retropubic operation. J Urol. 1958;79:308-14.

6. Warren MM, Greene LF. Calculus in the prostatic utricle. J Urol. 1972;107:82-4.

7. Lopatina OA, Berry TT, Spottswood SE. Giant prostatic utricle (utriculus masculinis): diagnostic imaging and surgical implications. Pediatr Radiol. 2004;34:156-9.

8. Salvarci A, Istanbulluoglu O. Monosymptomatic persistent hematospermia due to rarely encountered prostatic utricle stones. Urol Int. 2015;95:370-2. 